\title{
Emission scenarios for air quality management and applications at local and regional scales including the effects of the future European emission regulation (2015) for the upper Rhine valley
}

\author{
J.-L. Ponche ${ }^{1}$ and J.-F. Vinuesa ${ }^{1, *}$ \\ ${ }^{1}$ Laboratoire de Physico-Chimie de l'Atmosphère, Centre de Géochimie de la Surface, 1 rue Blessig, 67084 Strasbourg \\ Cedex, France \\ *now at: Saint Anthony Falls Laboratory, University of Minnesota, Minneapolis, USA
}

Received: 21 June 2004 - Published in Atmos. Chem. Phys. Discuss.: 23 December 2004

Revised: 28 February 2005 - Accepted: 4 March 2005 - Published: 23 March 2005

\begin{abstract}
Air quality modeling associated with emission scenarios has become an important tool for air quality management. The set-up of realistic emission scenarios requires accurate emission inventories including the whole methodology used to calculate the emissions. This means a good description of the source characteristics including a detailed composition of the emitted fluxes. Two main approaches are used. The so-called bottom-up approach that relies on the modification of the characteristics of the sources and the topdown approach whose goal is generally to reach standard pollutant concentration levels. This paper is aimed at providing a general methodology for the elaboration of such emission scenarios and giving examples of applications at local and regional scales for air quality management. The first example concerns the impact of the installation of the urban tramway in place of the road traffic in the old centre of Strasbourg. The second example deals with the use of oxygenated and reformulated car fuels on local (Strasbourg urban area) and regional (upper Rhine valley) scales. Finally, we analyze in detail the impacts of the incoming European emission regulation for 2015 on the air quality of the upper Rhine valley.
\end{abstract}

\section{Introduction}

Since the last decade, the air quality management and climate change control in industrialized countries have emerged as challenges. The improvement of the measures performed by the air quality survey networks, and the knowledge of the connection between public health and air pollution have encouraged the authorities in many countries to devise air

Correspondence to: J.-L. Ponche

(ponche@illite.u-strasbg.fr) quality improvement strategies. Air quality at a given place and time is driven by a combination of (1) meteorological and (2) climatological conditions that can be responsible for the long-range transport of pollutant, and (3) local emissions. Several recent studies have shown that regional air pollution and climate change are strongly linked to environmental policy, and the most efficient way to improve air quality is to control the emissions (Alcamo et al., 2002; Mayerhofer et al., 2002; Collins et al., 2000; Chang et al., 1998). Emission abatement strategies can be settled at various scales from continental down to local scales. To optimize strategies for air quality improvement (impacts and cost efficiency), it appears necessary to quantify their impacts at local or regional scales. If the background concentrations mainly depend on emissions at larger regional and continental scales (Derwent et al., 2004; Metcalfe et al., 2002), the regional and local air quality may also strongly depend on emissions at these scales, according to the climatological and geographic conditions (Schneider et al., 1997).

Since the reactive transport of pollutant is highly nonlinear, the evaluation of emission reduction strategies requires the use of air quality models to perform quantitative impact studies. The emission abatement scenarios are derived from existing emission inventories. The comparison of the results between existing emissions and scenarios allows one to quantify the impacts of emission scenarios on the pollutant concentration levels and to define the most accurate emission reduction scenarios according to air quality goals and cost effectiveness.

The elaboration of realistic scenarios with significant emission changes of selected chemical species or activities needs to have both a detailed description of all activities or sources that generate emissions and the chemical composi-

(C) 2005 Author(s). This work is licensed under a Creative Commons License. 
tion of the emitted fluxes. Two main approaches are currently used to derive emission scenarios. The first, so-called bottom-up approach, consists of the modification of the emissions at the most precise refined specification of the source. For instance, emission can be reduced by activities/sources, by adding/removing sources (Moussiopoulos et al., 1997; Gallardo et al., 1999) or by modifying the content of the energy supplier such as car fuel characteristics (Vinuesa et al., 2003). The second approach, the top-down, consists of the determination of the emission abatements necessary to reach a given pollutant concentration level. Even if these two approaches are complementary, since their primary objective is the improvement of air quality, the bottom-up approach is more useful to test technological and/or regulation changes.

The structure of the paper is as follows. In Sect. 2, we focus on emission inventories and the general method to create emission scenarios, and describe the relevant parameters of emission abatement strategies. In the following section, we briefly illustrate the method with some examples of possible applications. The main example of application, i.e. the French Regional Air Quality Plan (PRQA) for the Alsace region, is presented and analyzed in Sect. 4. There, the impact on photochemical air pollution on regional scale of the future European and National regulations, and the effects of supplementary regional abatement policy has been investigated. Finally, Sect. 5 gives a summary and presents the main conclusions of our study.

\section{Emission inventories and scenarios}

\subsection{Emission inventories}

Considering the lack of such inventories for France in the 90's, our general method was first based on existing local/regional Air Quality plans (Luftreinhaltplan) in Germany and Switzerland. Since the available databases to calculate emissions differ from country to country, it was necessary to develop our specific emission calculation method. We started with the transboundary region of the upper Rhine valley in the framework of the REKLIP project (REKLIP, 1995; Ponche et al., 1995, 2000). This method has been improved within the framework of several international and national programs as INTERREG I and II, PRIMEQUAL, French Regional Plan for Air Quality - PRQA of the Alsace region (Pallarès et al., 1999c), and also in collaboration with Moroccan University of Casablanca (Khatami et al., 1998) to reach the form presented in François et al. (2004).

This general method allows building up high spatial and temporal resolution local/regional emission inventories, favoring all the data at the finest level available, i.e. following the bottom-up approach. All activities or sources driving atmospheric emission are considered as far as data and emission factors exist or can be estimated. In case of a lack of adequate data, complementary data are collected at upper levels (regional or even national). The emission sources are classified with respect to the nomenclatures of the European Environmental Agency in order to be compatible at the European level. For stationary, biogenic and natural sources, the Selected Nomenclature for Air Pollution (SNAP) at the highest existing level (more than 250 different activities and processes) is used together with the Nomenclature for Air Pollution of Fuels (NAPFUE). This approach allows a better description of the activities of the sources with the different fuel consumptions (EEA, 2002). For mobile sources, the COPERT classification (EEA, 2000) appears to be the most refined existing method for Europe and is optimized for air quality management in terms of database structure and additional software management tools. Thus, the extraction, actualization, and modification of sources and related emissions per SNAP/NAPFUE-COPERT categories are facilitated.

\subsection{Emission scenarios}

To build relevant and accurate emission scenarios, two conditions must be satisfied. First, the description of the sources and their emissions must be sufficiently detailed and structured to allow the calculation of modified emissions at the finest level. This is essential in calculating the emission changes defined in the abatement plans and obtaining realistic and consistent emission scenarios. Second, the air quality models used to quantify the impact of the scenarios must have a chemical mechanism relevant to the chemical make up of the emissions. The impact of emission abatement strategies is usually determined by comparing the results of such models using a base case emission (reference inventories) and emission scenarios. Thus, the models must be able to calculate significant differences for some pollutant concentration fields when emissions are changed from reference to scenarios. In summary, consistency between the sensitivity of the model, emission chemical speciation of the inventories and realistic scenarios are required to investigate the impacts of emission abatement strategies.

However, for emission inventories, it is essential to precisely define the goals of the emission abatement strategy to build accurate emission scenarios. In particular, it is necessary to point out the chemical compounds or groups of compounds concerned, or any changes in the sources or categories of sources (activities) which will have to be taken into account. The first step is to identify the parameters for each category of sources driving the emission levels, which can be modified according to the objectives of the study.

The emissions are generally calculated from the following equation

$E_{p, S, \Delta t}=A_{p, \Delta t} E F_{p, S, \Delta t}$

where $E_{p, S, \Delta t}$ represent the quantitative emission of a chemical compound (pollutant) $p$ from the source or category of source $S$ whose activity factor $A_{p, \Delta t}$ is proportional to the emission during the time step $\Delta t . E F_{p, S, \Delta t}$ is the emission 
Table 1. Principal parameters involved in the emission scenario calculations.

\begin{tabular}{|c|c|c|}
\hline \multirow{2}{*}{$\begin{array}{l}\text { Sources } \\
\text { Parameter }\end{array}$} & \multicolumn{2}{|c|}{ Source characteristics related to the emission generation } \\
\hline & Intrinsic parameters & External Parameters \\
\hline \multicolumn{3}{|c|}{ Stationary sources } \\
\hline Industry & $\begin{array}{l}\text { Production index/production } \\
\text { Industry processes } \\
\text { Installation combustion type (power, } \mathrm{T}^{\circ}, \ldots \text { ) } \\
\text { Emissions reducing devices } \\
\text { Solvent recovering devices } \\
\text { Technical and technological improvement }\end{array}$ & $\begin{array}{l}\text { Fuels, solvents } \\
\text { Number of employees } \\
\text { Outdoor temperature } \\
\text { Energy self-production }\end{array}$ \\
\hline $\begin{array}{l}\text { Residential } \\
\text { commercial and } \\
\text { institutional }\end{array}$ & $\begin{array}{l}\text { Thermal characteristics of the building } \\
\text { Collective building / individual houses } \\
\text { Type of warm water production device } \\
\text { Domestic uses of solvents }\end{array}$ & $\begin{array}{l}\text { Indoor/outdoor temperature difference } \\
\text { Fuels } \\
\text { Heating system }\end{array}$ \\
\hline \multicolumn{3}{|c|}{ Mobiles sources/transports: } \\
\hline Road traffic & $\begin{array}{l}\text { Vehicle fleet composition } \\
\text { Road network (types of road and slopes) } \\
\text { Engine technologies } \\
\text { Mean length travels (urban) } \\
\text { Emission reducing devices, converters }\end{array}$ & $\begin{array}{l}\text { Fuel types } \\
\text { Outdoor temperatures } \\
\text { Average velocities } \\
\text { Road counting }\end{array}$ \\
\hline Air traffic & $\begin{array}{l}\text { Airplane type } \\
\text { Engine type }\end{array}$ & $\begin{array}{l}\text { Characteristics of the LTO cycle } \\
\text { Fuels, total number of movements }\end{array}$ \\
\hline Other traffics & $\begin{array}{l}\text { Engine technologies } \\
\text { Network }\end{array}$ & $\begin{array}{l}\text { Characteristic of the movements } \\
\text { Fuels, total number of movements }\end{array}$ \\
\hline \multicolumn{3}{|l|}{ Biogenic/nature } \\
\hline Forest & $\begin{array}{l}\text { Species } \\
\text { biomass density }\end{array}$ & $\begin{array}{l}\text { Temperature } \\
\text { Solar irradiation }\end{array}$ \\
\hline Agriculture & $\begin{array}{l}\text { Species } \\
\text { Use of fertilizers }\end{array}$ & $\begin{array}{l}\text { Temperature } \\
\text { Solar irradiation }\end{array}$ \\
\hline Soil & Moisture of soil / relative humidity & Wind velocity, Temperature \\
\hline Breeding & $\begin{array}{l}\text { Animal types } \\
\text { Extensive intensive breeding }\end{array}$ & Livestock \\
\hline Nature & $\begin{array}{l}\text { Species } \\
\text { biomass density }\end{array}$ & $\begin{array}{l}\text { Temperature, wind velocity, relative humidity } \\
\text { Solar irradiation }\end{array}$ \\
\hline
\end{tabular}

factor which links the activity of the source and the emission of $p$ during $\Delta t$. In this equation, one can modify the emissions by changing the activity of the sources, the characteristics, the location or the emission factors of the sources. However, Eq. (1) can be more complex and can involve several parameters included in the activity or in the emission factor, which leads to various scenarios. The parameters can be grouped into two categories:

- Intrinsic parameters. They are specific to the characteristics of the sources and the emission generation processes. These parameters are usually related with the emission factors.
- External parameters. They can change the emission levels, independently of the source characteristics. These parameters are usually included in the activity factors.

Table 1 gives a summary of the parameters used in emission inventories which can be modified to generate different emission scenarios. One comment can be necessary to precise one point concerning the transport source category: the counting (number of vehicle per unit time) for the road traffic and the number of movements for the other traffics are generally considered as external parameters. Nevertheless, it can also be assumed as intrinsic ones when the counting or the number of movements for each detailed categories of mobile 


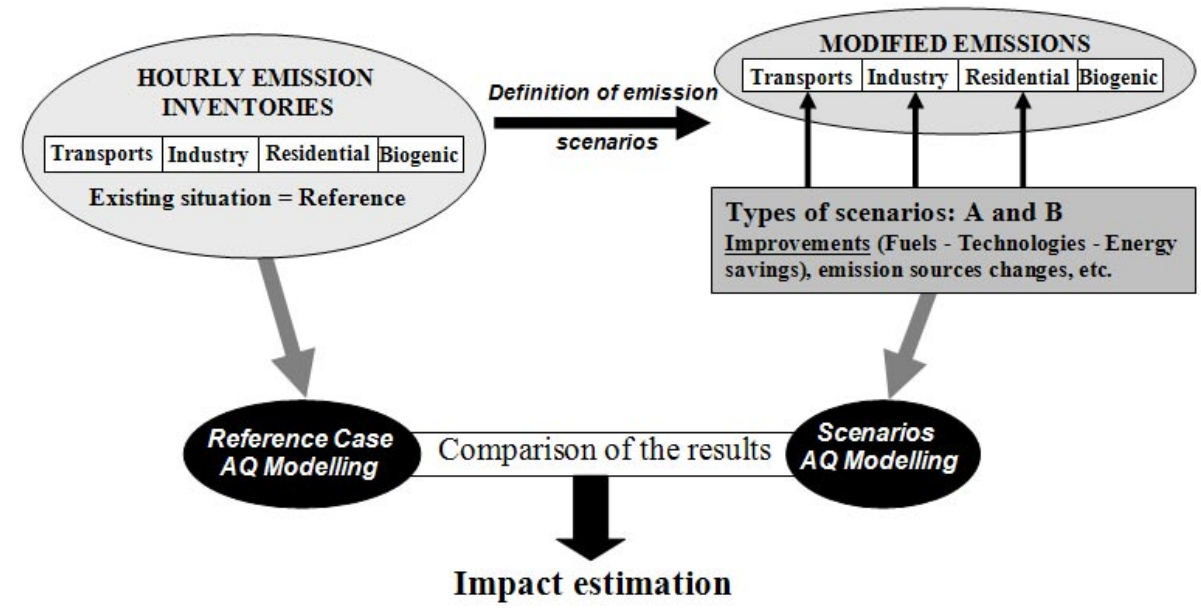

Fig. 1. General method of impact assessment using emission reference and scenarios.

sources are used to elaborate emission factors of the whole fleet of mobile sources. One can notice that for several source categories, the emissions depend on meteorological parameters such as temperature, solar radiation or wind velocity. This means that the meteorological conditions can modify the emitted fluxes of these sources. Some of them are controlled by meteorological parameters, such as biogenic and natural sources. These latter parameters are not considered when creating scenarios, but generally they are used to perform sensitivity analyses of the emissions. Modifying them allows one to quantify the variability of these emissions related to the environmental conditions. Thus, the dependence of the emissions on these parameters can be evaluated and the accuracy of the parameters can be defined to avoid large emission uncertainties. For instance, since the emissions of a large surface source such as a forest depend on the temperature, their calculation requires the knowledge of the temperature over the whole area concerned. As the sensitivity of this parameter (depending on the tree species constituting the forest) is important, the description of the temperature field over the area must be accurate to minimize the uncertainties on the emissions.

2.3 The main types of air quality management emission scenarios

According to the goals of the emission abatement strategy and further use of the emission scenarios, different ways of creating emission scenarios are possible. The main types can be derived from existing emissions on different time frames: yearly down to hourly. Since our main research interest deals with air quality management at the mesoscale, we will focus on middle and short term strategies. In that respect, the scenarios are based on the following changes of the parameters previously described:

- modification of emission factors $\left(E F_{p, S, \Delta t}\right)$ related to changes of the source characteristics such as the com- position of the fuels, technology improvements (processes, engines, reduction emission devices, etc.), energy savings, the use of solvent recovery devices for anthropogenic sources, and vegetation species in forest and agriculture for biogenic sources,

- modification of the sources' activities $\left(A_{p, \Delta t}\right)$ such as the production, traffic volume changes, and biomass factors changes,

- changes of the intrinsic source characteristics: processes, fuels, mobile source fleet, vegetation species,

- localization of the emission sources: break down of activities, new source locations, land use changes (urban, agriculture, forest area, water surface modifications). Note that the land use changes may also have climatological impacts which can induce feedback on emissions through albedo, ground temperature, heat changes,

- modification of the time distributions of the emission with all intrinsic parameters unchanged.

The other aspects of the creation of emission scenarios concern the purpose of the air quality management and/or the abatement strategies. First, the emission scenarios can focus on one or more particular source categories to assess the impact of emission changes for these sources. This type of scenario is very useful to quantify the impact of regulations on specific emission sources. Second, the construction of the scenarios can be based on regulation goals to be applied in terms of concentration or emission levels. In case of emission abatement, the sources have to be modified (activities, emission factors) to reach theses levels. The goal is to quantify the improvements generated by this regulation. Another use of this method of creation is to orient a scenario to concentration or exposure levels to be reached. This can be 


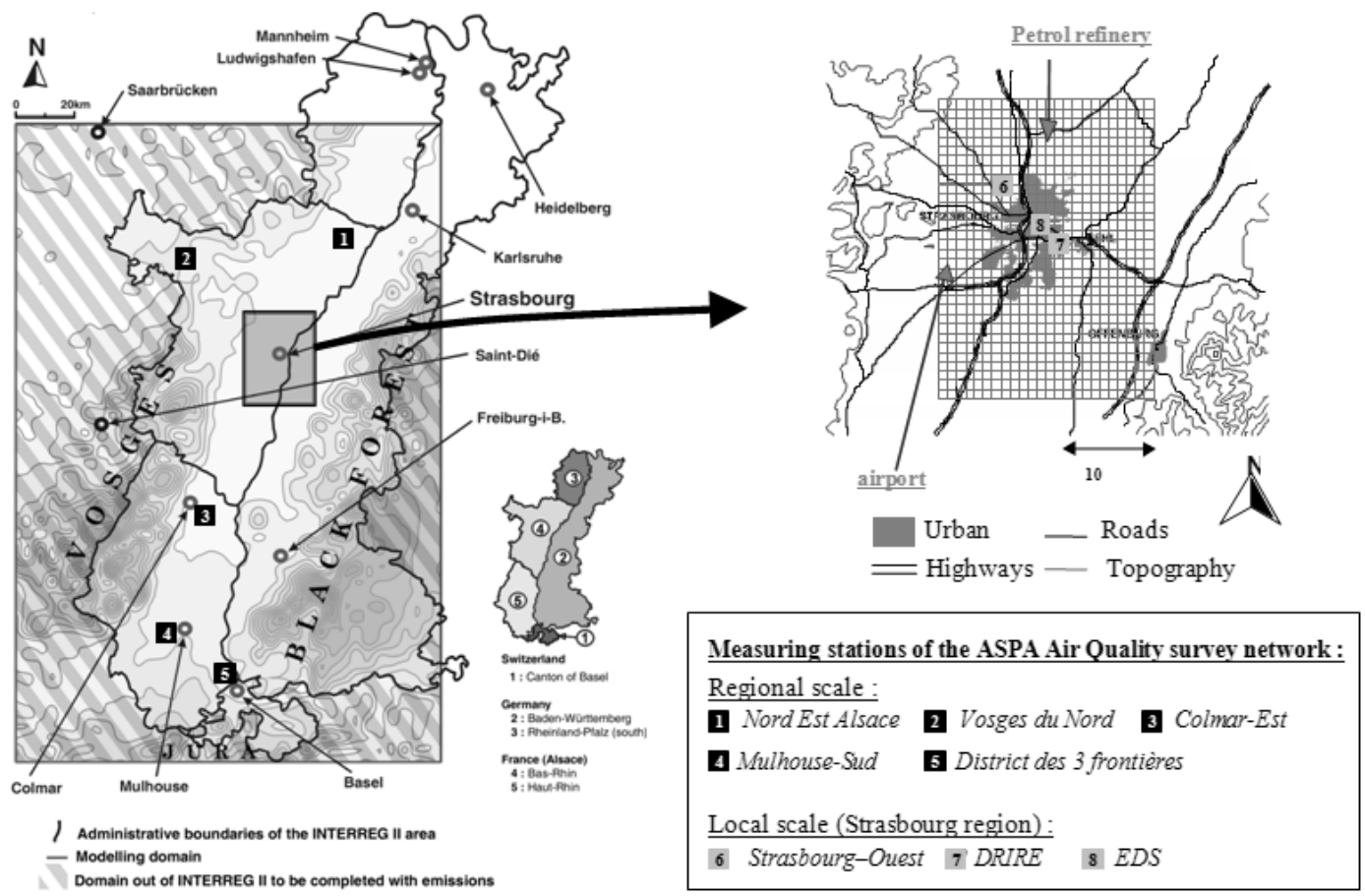

Fig. 2. Geographical location of the regional and local investigation domains.

very complex since different approaches can be used to modify emission levels, the chemical composition of emissions (to decrease specific secondary pollutants) or the emission time distributions according to meteorological conditions (to favor efficient dispersion of pollutants). In this case, several scenarios have to be tested to obtain the most efficient way to reach the objectives, especially if cost effectiveness is a concern.

\section{Scenarios and air quality modeling}

In this section, we present two examples of applications of emission scenarios. The emission scenarios consider the change of one specific emission category and their impact on air quality at local and regional scales. Both reference case emissions and scenarios are then used as input data to the chemical mechanism of the air quality model. The last step is the comparison of the respective simulated pollutant concentration fields to assess the impacts of emission changes (Fig. 1). The first example concerns the impact of the installation of an urban tramway instead of the road traffic in the old centre of Strasbourg (Gallardo, 2000), and the second deals with the impacts of using modified car fuels (oxygenated and reformulated fuels) at local (Strasbourg urban area) and regional (upper Rhine valley) scales (Vinuesa, 2000; Vinuesa et al., 2003). All the simulations use the model EUMAC Zooming Model - EZM (Moussiopoulos, 1995) composed of two independent models: a meteorological mesoscale model MEMO and a reacting transport model
MARS. Different chemical mechanisms have been used to fit with the goal of each study.

\subsection{Areas and period of interest}

The regional domain of investigation is the whole upper Rhine valley (Fig. 2). This area of $144 \mathrm{~km}$ (EastWest) $\times 216 \mathrm{~km}$ (North-South) regroups parts of three countries: Switzerland, Germany and France. It is a densely populated (about 6.3 million inhab. and 300 inhab. $\mathrm{km}^{-2}$ ) and industrialized region. The Alsace region is located in the western part of the upper Rhine valley and regroups $1.71 \mathrm{M}$. inhabitants on about $8250 \mathrm{~km}^{2}$. Two main highways cross north to south this valley and draw heavy local and transborder road traffic. The upper Rhine valley is surrounded by three mountainous chains: the Vosges (west), the Black forest (south east) and the Jura (east south). The modeling domain has been chosen to preserve the geographical and dynamic unity of the valley. The topography allows the emergence of frequent temperature inversion especially under anticyclonic weather conditions. For several years, emission abatement strategies appeared necessary given the increase of photochemical pollution episodes. Also, this region is very sensitive to air pollution due to these meteorological and climatological conditions (Adrian and Fiedler, 1991; Schneider et al., 1997). Further information can be found in REKLIP (1995, 1999), and Ponche et al. (2000).

The local domain is included in the regional one and consists of the German-French urban area of StrasbourgOffenburg. It has been selected to allow the study of emission 
Table 2. Summary of the emission inventory used for the extended urban area of Strasbourg, extracted from the hourly REKLIP emission inventory for the 16 September 1992.

\begin{tabular}{lcccc}
\hline Emission Sources & \multicolumn{4}{c}{ Emissions for the 16.09 .1992 in $\mathrm{t} /$ day } \\
& $\mathrm{SO}_{2}$ & $\mathrm{NO}_{\mathrm{x}}$ & $\mathrm{VOC}$ & $\mathrm{CO}$ \\
\hline Road and air Traffic $^{1}$ (Exhausts and evaporation) & 2.29 & 33.89 & 24.86 & 112.61 \\
Points source emissions (combustion and processes) & 24.34 & 5.55 & 6.98 & 1.14 \\
Area sources emissions (including other industries, residential and service sectors) & 8.38 & 2.82 & 3.60 & 2.68 \\
Total & 35.01 & 42.26 & 35.44 & 116.43 \\
\hline
\end{tabular}

1 Airport contribution represents between $1-4 \%$ of the total traffic emissions for the different compounds.
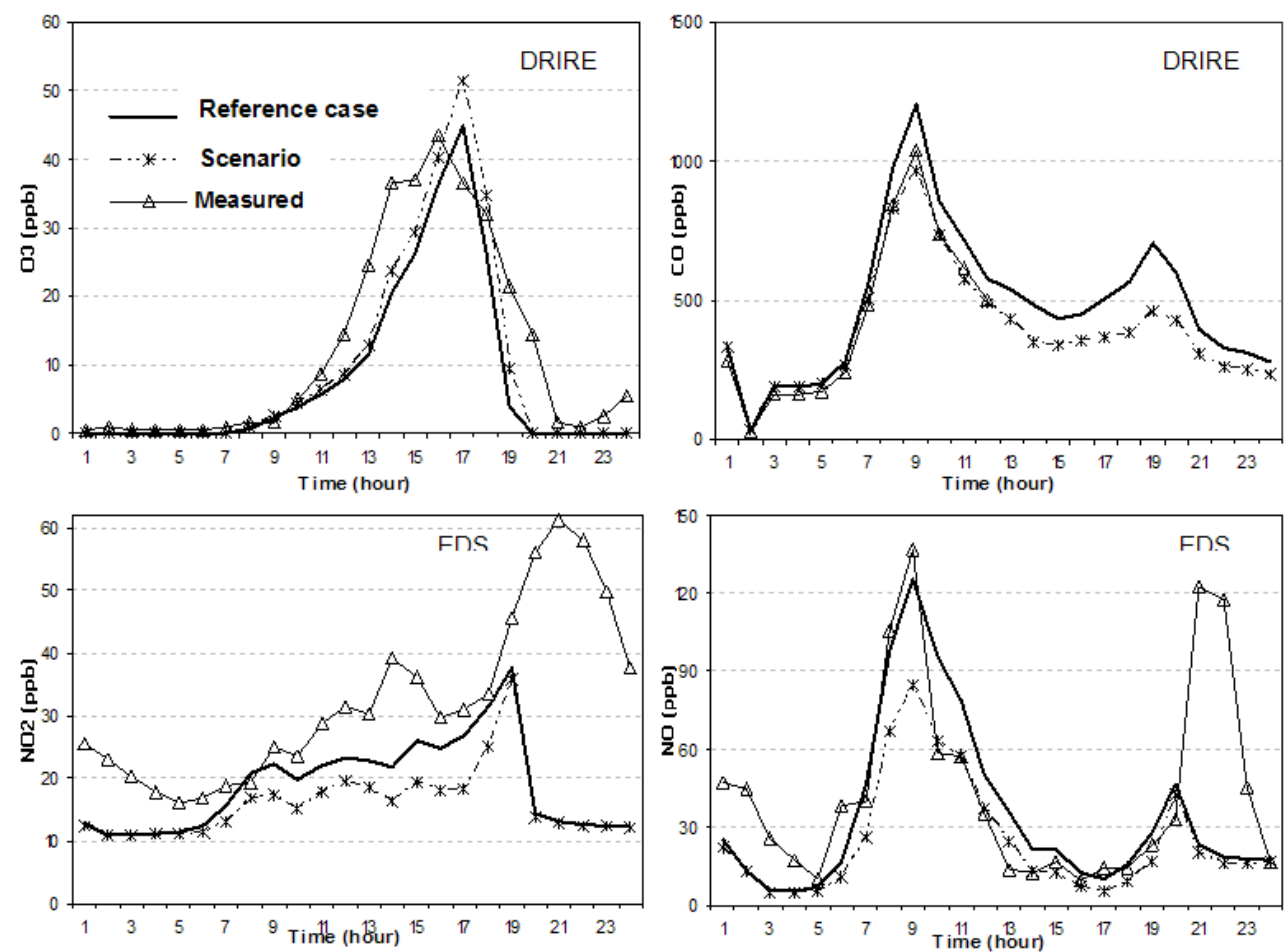

Fig. 3. Impact of the road traffic change in the Centre of Strasbourg (Scenario) compared with the reference case simulation (Computed) and concentration measurements (Measured) of $\mathrm{O}_{3}$ (upper left), $\mathrm{CO}$ (upper right), $\mathrm{NO}_{2}$ (lower left) and $\mathrm{NO}$ (lower right) at two stations (DRIRE and EDS) of the ASPA air quality measuring network. These two stations are located in the Centre of Strasbourg (see Fig. 2).

impacts over a typical urban area. This domain is located across the Rhine river and includes the urban community of Strasbourg (420000 inhab.), the communities and cities (Offenburg and Kehl) of the administrative district Ortenau (90 000 inhab.) and the other communities around the administrative limits to complete the square domain (44000 inhab. for the French part and 16000 for the German part). The area covers $24 \mathrm{~km}$ (East-West) $\times 32 \mathrm{~km}$ (North-South) and the total number of inhabitants was about 590000 in 1995.

The results of the impact studies presented in the following are summarized from previous works dealing with the photochemical pollution episodes of 15-16 September 1996 and of 9-15 May 1998. During these periods, the anticyclonic conditions were favoring photochemical pollution, i.e. northeastern low wind flows all over the region with temperature about 3 to $5^{\circ} \mathrm{C}$ above the seasonal average. The low wind velocities and strong temperature inversion prevented the dispersion of the emitted pollutants (especially issued from urban area and heavy traffic sources). For example, during the May 1998 episode, these summer-like conditions led to 28 overflows of the information threshold of the ozone directive of the European Union $\left(180 \mu \mathrm{g} \mathrm{m}^{-3} \times 1 \mathrm{~h}\right.$ of ozone exposition) in the urban area of Strasbourg. 
Table 3. Brief overview of the results obtained for the main chemical species at local (urban area of Strasbourg) and regional (upper Rhine valley) scales.

\begin{tabular}{|c|c|c|c|c|c|c|c|c|c|c|c|c|c|c|c|c|c|c|c|}
\hline & & \multicolumn{9}{|c|}{ Scenario at local scale } & \multicolumn{9}{|c|}{ Scenario at regional scale } \\
\hline & & 1 & 2 & 3 & 4 & 5 & 6 & 7 & 8 & 9 & 1 & 2 & 3 & 4 & 5 & 6 & 7 & 8 & 9 \\
\hline \multicolumn{2}{|l|}{ Modified fuels (gasoline) } & \multicolumn{3}{|c|}{ ETBE1 } & \multicolumn{3}{|c|}{ | ETBE2 } & \multicolumn{3}{|l|}{ R2 } & \multicolumn{3}{|c|}{ | ETBE1 } & \multicolumn{3}{|c|}{ ETBE2 } & \multicolumn{3}{|l|}{ I R2 } \\
\hline \% of the vehicle fleet & & 50 & 80 & 100 & 50 & 80 & 100 & 50 & 80 & 100 & 50 & 80 & 100 & 50 & 80 & 100 & 50 & 80 & 100 \\
\hline \multirow{2}{*}{$\mathrm{O} 3$} & Maxima & + & + & + & + & ++ & ++ & + & + & ++ & ++ & ++ & + & + & ++ & Und. & Und. & + & + \\
\hline & Background & + & + & ++ & + & + & ++ & Und. & + & ++ & ++ & ++ & + & + & + & Und. & Ind. & + & + \\
\hline \multirow{2}{*}{$\mathrm{CO}$} & Maxima & ++ & ++ & +++ & ++ & +++ & +++ & ++ & ++ & ++ & - & - & Und. & - & -- & - & - & - & - \\
\hline & Background & ++ & ++ & ++ & ++ & ++ & ++ & ++ & ++ & ++ & + & + & + & - & - & - & - & - & - \\
\hline \multirow{2}{*}{ NO } & Maxima & - & - & - & - & - & $\ldots$ & - & -- & - & - & - & Und. & - & -- & Und. & - & - & - \\
\hline & Background & - & - & - & -- & -- & $\cdots$ & - & $-\cdots$ & - & - & -- & - & - & $\cdots$ & - & - & - & - \\
\hline \multirow{2}{*}{$\mathrm{NO} 2$} & Maxima & Und. & Und. & Und. & Und. & Und. & -. & Und. & Und. & Und. & - & -- & - & - & $-\ldots$ & - & - & - & - \\
\hline & Background & Und. & Und. & Und. & Und. & Und. & $\cdots$ & Und. & Und. & Und. & - & \begin{tabular}{|l|}
$-\cdot$ \\
\end{tabular} & - & - & - & - & - & - & - \\
\hline \multirow{2}{*}{ PAN $^{1}$} & Maxima & + & ++ & ++ & + & ++ & ++ & ++ & ++ & ++ & ++ & +++ & ++ & + & ++ & + & + & ++ & ++ \\
\hline & Background & + & + & + & + & + & ++ & + & + & ++ & ++ & +++ & ++ & + & + & $\mathrm{O}$ & + & ++ & ++ \\
\hline \multirow{2}{*}{ Total VOC } & Maxima & ++ & +++ & +++ & ++ & ++ & +++ & ++ & +++ & ++ & +++ & +++ & ++ & + & + & ++ & ++ & ++ & ++ \\
\hline & Background & ++ & ++ & +++ & ++ & ++ & +++ & + & ++ & + & +++ & +++ & ++ & ++ & ++ & ++ & ++ & ++ & ++ \\
\hline \multirow{2}{*}{ Total Alkenes } & Maxima & - & - & $\ldots$ & Und. & - & + & $\ldots$ & $\ldots$ & .. & - & - & - & $\ldots$ & $\ldots$ & - & $\ldots$ & $\ldots$ & $\ldots$ \\
\hline & Background & Und. & Und. & Und. & Und. & Und. & ++ & - & - & - & $-\cdots$ & $--\cdot$ & - & $\cdots$ & $\cdots$ & - & $\cdots$ & $\cdots$ & $\cdots$ \\
\hline \multirow{2}{*}{ Light $\mathrm{HC}(\mathrm{C}<5)^{2}$} & Maxima & ++ & ++++ & +++ & + & + & ++ & Und. & ++ & + & ++ & ++ & Und. & Und. & Und. & Und. & - & - & - \\
\hline & Background & ++ & +++ & +++ & + & + & ++ & Und. & + & + & +++ & +++ & ++ & + & + & Und. & Und. & Und. & Und. \\
\hline \multirow{2}{*}{ Others $\mathrm{HC}$ incl. aromatics } & Maxima & +++ & +++ & +++ & +++ & +++ & +++ & +++ & +++ & +++ & ++ & ++ & + & ++ & +++ & + & ++ & +++ & +++ \\
\hline & Background & ++ & ++ & ++ & ++ & ++ & ++ & ++ & ++ & ++ & ++ & +++ & ++ & +++ & +++ & ++ & +++ & +++ & +++ \\
\hline \multirow{2}{*}{ Formaldehyde (HCHO) } & Maxima & + & + & + & Und. & Und. & + & Und. & Und. & + & + & + & + & Und. & - & + & Und. & Und. & Und. \\
\hline & Background & + & + & + & Und. & + & + & + & + & + & ++ & ++ & + & Und. & - & + & Und. & Und. & Und. \\
\hline \multirow{2}{*}{ Total Aldehydes } & Maxima & Und. & Und. & Und. & Und. & Und. & + & Und. & + & Und. &.- & $\ldots$ & - & $\ldots$ & $\ldots$ & $\mathrm{O}$ & Und. & Und. & Und. \\
\hline & Background & + & + & $1+$ & Und. & Und. & $1+$ & Und. & + & Und. & - & - & $1-$ & -- & -- & 0 & $\mathrm{O}$ & + & + \\
\hline \multirow{2}{*}{ Ketones } & Maxima & + & ++ & ++ & + & ++ & + & + & + & + & +++ & +++ & ++ & ++ & +++ & ++ & ++ & +++ & +++ \\
\hline & Background & ++ & ++ & ++ & + & ++ & ++ & + & + & + & +++ & +++ & ++ & ++ & +++ & ++ & ++ & +++ & +++ \\
\hline
\end{tabular}

1 PAN: peroxy-acetyl-nitrate

${ }^{2} \mathrm{HC}$ : hydrocarbons (number of carbon $\mathrm{C}<5$ )

Und.: Undefined impact, the spatial distribution does not allow aclear trend on the whole domain.

O: no significant impact on the whole domain

,,++++++ : more and more positive impact s (reductions of simulated concentrations)

,,------ : more and more negative impacts (increases of simulated concentrations).

\subsection{Impact of local road traffic changes}

In view of the building of the tramway through the old part of the city, which included the removal of all road traffic in this old centre of Strasbourg ( $6 \mathrm{~km}^{2}$ of dense small streets), some scenarios have been elaborated to assess the future impact of this road traffic change. A high resolution emission inventory $\left(1 \times 1 \mathrm{~km}^{2} \times 1 \mathrm{~h}\right)$ was established for 16 September 1992 corresponding to an ozone pollution episode (see Table 2). This inventory was created from the REKLIP hourly emission inventories (Ponche et al., 1995, 2000). The road traffic from the old city centre has been displaced around the centre with the help of a rough traffic model to preserve the consistency of the road traffic volume. Thus, the total hourly emissions have not been significantly decreased; only the spatial distribution has been changed. The simulations have been performed with EZM and with the chemical mechanism KOREM (Flassak et al., 1993). The results at two representative locations of the centre of Strasbourg are summarized in Fig. 3. The simulated impact of this change is very limited and concerns only the domain where the emission reductions (road traffic) have been applied (curves "Scenario" in Fig. 3). It has led to a small increase of the ozone peak and a decrease of $\mathrm{NO}_{\mathrm{x}}$ and $\mathrm{CO}$ concentrations levels. A complete description of this study can be found in Gallardo (2000).

\subsection{Impact of local and regional emission changes due to modified car fuels}

Another example to illustrate the impact study of different emission scenarios is the study performed within the framework of the French program AGRICE (Agriculture for Chemistry and Environment). This study aims at quantifying the possible impacts of using three modified car fuels: a gasoline car fuel named ETBE1 containing 15 weight \% of Ethyl tertio-butyl Ether (ETBE), a reformulated gasoline (R2), and one both reformulated and containing ETBE (so called ETBE2). The use of alternative fuels has been suggested at the end of the eighties in order to improve urban air quality by reducing combustion-related pollution. Indeed, reformulating the fuel (modification of the chemical composition of the fuel, e.g., by lowering of the aromatic fraction, and/or addition of oxygenated compounds, as here the ethyltertio-butyl-ether or ETBE) allows the modification of the composition of the emissions due to the road traffic. Only a brief overview is given below and all further details can be found in Vinuesa (2000) and in Vinuesa et al. (2003). The 


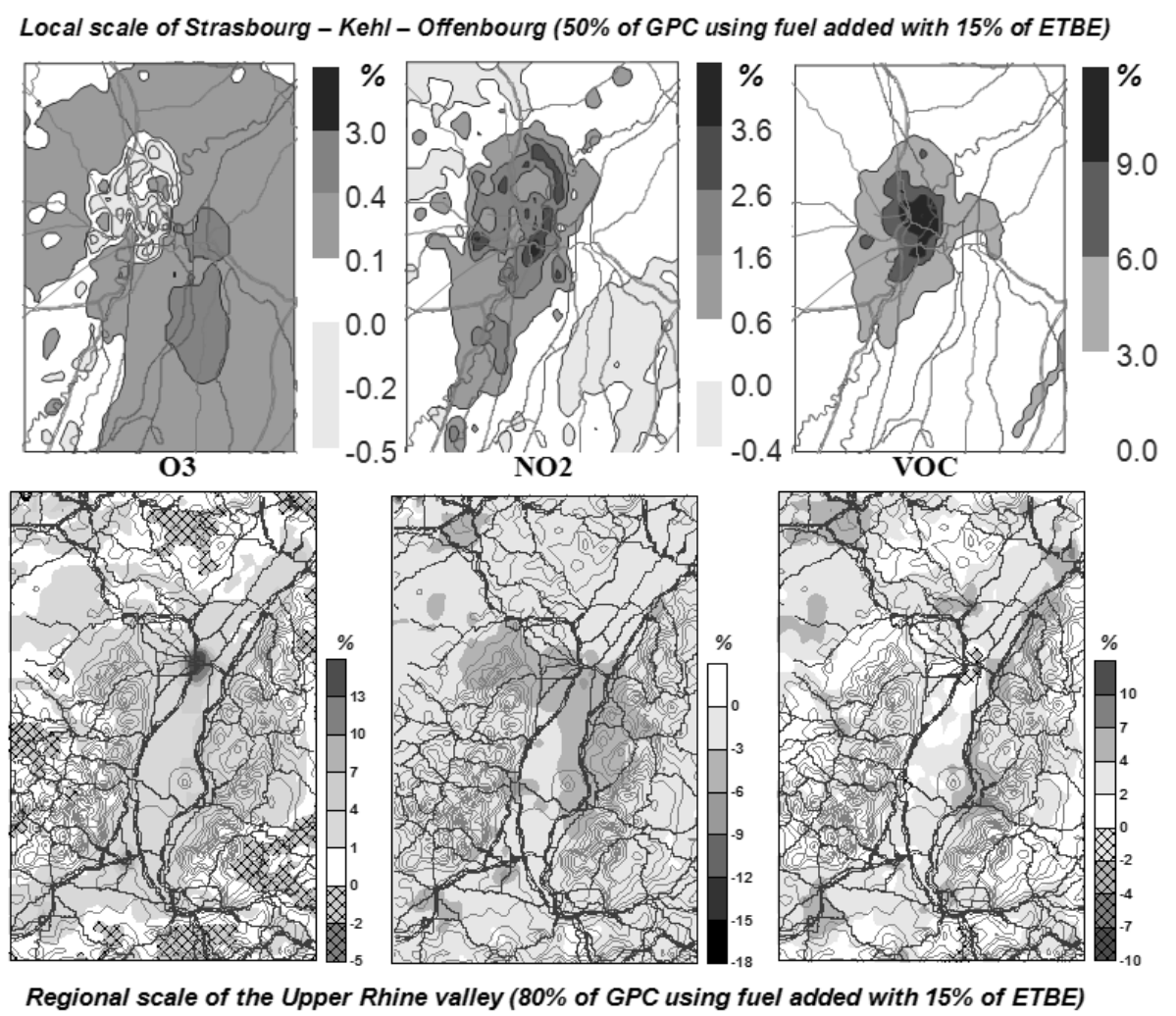

Fig. 4. Example of quantified impacts on daily average concentrations of $\mathrm{O}_{3}, \mathrm{NO}_{2}$ and VOC obtained for the car fuel added with 15 weight $\%$ of ETBE (without reformulation) used by $50 \%$ and $80 \%$ of the gasoline passenger car fleet at local and regional scales, respectively. Positive negative values, respectively, corresponds to decrease - increase of concentrations compared to the simulation with the reference emission inventory.

scenarios have been created from the PRIMEQUAL and INTERREG II emission inventories at local scale, i.e. the Strasbourg area, and regional scale, i.e. the upper Rhine valley, respectively. The existing emission inventories have been considered a reference. Then, the road traffic contribution from the gasoline passenger cars has been extracted and modified to take into account different fleet car fractions using these modified fuels (30, 50, 80 and $100 \%$ at local scale).

Table 3 gives an overview of the results obtained at local and regional scales. These results show that the major positive impacts (reduction of resulting concentrations) on air quality at the local scale were obtained when more than $50 \%$ of the vehicle fleet is using modified car fuels. In the urban area the road traffic contribution is much more important compared to the regional scale. Thus, the impacts obtained at local and regional scales vary somewhat due to the differences in spatial distribution emissions. At local scale, the VOC (up to $20-25 \%$ for background concentrations, and $45 \%$ for the peak concentrations) especially the aromatic fraction, the $\mathrm{CO}(8-12 \%$ and $25 \%$, respectively), are reduced. Lower concentration reductions are simulated for the ozone (1-3 and 3-6\%, respectively) the ketones, and the peroxy-acethyl-nitrate (PAN). On the contrary, global negative impact trends (increase in concentrations) have been obtained for $\mathrm{NO}_{\mathrm{x}}$ and the alkenes, even if very locally, some positive impacts are simulated. For aldehydes, there is no clear trend. At regional scales, positive impacts are obtained for the VOC, PAN and ketones similar to what is obtained at local scale and the reduction of ozone levels is still small. However for $\mathrm{NO}_{\mathrm{x}}$, alkenes, $\mathrm{CO}$ and the total aldehyde group, significant negative trends are found. This study has allowed quantifying the possible effects of these modified fuels used by different fractions of the gasoline passenger car fleet as illustrated in Fig. 4.

\section{The 2015 European emission regulations applied to the upper Rhine valley}

In France, since the Law on air and the rational use of energy has been established in 1995, each region and major city (over 200000 inhabitants) have to define a Regional Plan for Air Quality (PRQA) and Atmospheric Protection Plan (PPA), respectively. These regulations are generally intensifying the existing European guidelines on air quality, to reach the objectives defined for the whole EEC. Within the framework of the PRQA of the Alsace region, the Regional Direction of 
Table 4. Total daily emissions in tons per day for the 11 May 1998 for the whole INTERREG II domain.

\begin{tabular}{|c|c|c|c|c|}
\hline \multirow[t]{2}{*}{ Emission sources } & \multicolumn{4}{|c|}{ Total daily emissions (t/day) } \\
\hline & $\mathrm{SO}_{2}$ & $\mathrm{CO}$ & VOC & $\mathrm{NO}_{\mathrm{x}}$ \\
\hline Combustion in the large point sources & 177,6 & 25,8 & 77,2 & 91,0 \\
\hline Combustion in energy public power (electricity) and other energy transformations & 10,1 & 2,5 & 1,0 & 4,1 \\
\hline Combustion in the residential plants: combustion plants $<50 \mathrm{MW}$ (boilers) & 17,2 & 189,0 & 28,9 & 15,9 \\
\hline Combustion in manufacturing industries (boilers, gas turbine and stationary engines) & 17,3 & 11,9 & 10,9 & 20,5 \\
\hline Production processes (all) & 2,5 & 0,1 & 5,7 & 12,9 \\
\hline Liquid fuel distribution (including gasoline distribution) and gas distribution networks) & 0 & 0 & 45,9 & 0 \\
\hline Solvent and other product uses & 0,6 & 0,8 & 212,5 & 2,5 \\
\hline Road transport & 13,8 & 903,5 & 174,3 & 231,2 \\
\hline Other mobile sources and machineries & 0,9 & 17,5 & 5,0 & 18,6 \\
\hline Waste treatment and disposal & 0,3 & 5,6 & 164,8 & 1,5 \\
\hline Agriculture and forestry, land use and land-use changes & 0 & 0 & 321,2 & 0 \\
\hline Nature & 0 & 0 & 9,2 & 0 \\
\hline Total & 240,2 & 1157 & 1056,7 & 386,5 \\
\hline
\end{tabular}

Research, Industry and Environment (DRIRE) of Alsace has charged our Laboratory to perform impact studies of abatement strategies on the upper Rhine valley. The present study has two main objectives: (1) to determine the changes in ozone and $\mathrm{NO}_{\mathrm{x}}$ levels if the future European regulations (referring to the year 2015) would have been applied for the whole area during the photochemical episode of the 9-15 May 1998 and (2) to provide a practical example, that can be included in a PRQA, of the benefits of using air quality modeling coupled with emission scenarios for air quality management. For this purpose, emission reduction scenarios have been elaborated jointly with the "Prefecture" (which are the executive state authorities), the DRIRE (charged to check the application of the formal directives), the Centre d'Etude Technique de l'Equipement (CETE) de l'Est (charged with all questions regarding the road transport including the road management network out of the cities) and the Association de Surveillance et d'études de la Pollution Atmosphérique (ASPA) of the Alsace region which is in charge of the survey and measuring air quality network. The modified emission inventories are used as input data in simulations performed with the EZM air quality model and the results are compared with the base case modeling using the existing emission inventory.

\subsection{The PRQA emission scenarios}

The emission scenarios are based on the hourly emission inventories created for the period of 9-15 May 1998 (Table 4) and for the air quality modeling of this ozone episode (Pallarès et al., 1999a, b). These hourly emission inventories are derived from the yearly INTERREG II emission inventories (INTERREG II, 2000; Pallarès et al., 1999c). The INTERREG II emission database is a $1 \mathrm{~km} \times 1 \mathrm{~km}$ emission inventory for the whole upper Rhine valley for the reference year
1997 and includes both anthropogenic and biogenic sources. Both time distribution functions and hourly data are used to reach the hourly resolution. As far as hourly data are available, they allow us to calculate specific hourly emissions. In case of missing data, representative time function distributions are created according to complementary data on the activities and behaviors of the emission sources. The emission and activity sources are classified using the European nomenclature SNAP 97 (Selected Nomenclature for Air Pollution actualized in 1997). Special attention is devoted to orient this emission database structure to spare actualization procedures including emission scenario generation. Two emission scenarios, both referring to the year 2015, are used. The first scenario (SC1) describes the evolution of the emissions when only the incoming European emission evolution and regulations are taken into account. The second (SC2) is based on the same evolution, but with additional constraint of local and regional regulations about pollutant emissions. The results obtained for these new emissions inventories are summarized in Table 5.

In SC1, the emissions due to the fixed installation of combustions are issued from three sectors: industry, residential (individual housing) and service sectors. The sulphur content of heating oil ( $0.2 \mathrm{wt} \%$ for the base case) has been lowered to $0.1 \mathrm{wt} \%$ in all combustion processes involved in these latter sectors. Incoming improvements in heating technology are supposed to reduce the $\mathrm{NO}_{\mathrm{x}}$ emissions by $2 \%$ and the $\mathrm{CO}$ emissions between 3 and $8 \%$ for some activity sectors. For chemical industrial processes, the $\mathrm{NO}_{\mathrm{x}}$ emissions are reduced by $5 \%$ except for cement and paper factories where the reductions reach $30 \%$ and $50 \%$. For the point sources, the use of natural gas increases and the other fuels are reduced by $8 \%$ in TOE (Tons Oil Equivalent). For the waste treatment sector, emissions of VOCs are reduced by a factor of 2 except for domestic waste incinerators where emission 
Table 5. Weighting factors per code SNAP3 level description 3) concerned by the application of the regulations for the SC1, SC2 and relative differences (in \%) of SC2 compared to SC1. The emission level references are those of 1998 which correspond to 1.00. This table contains only the emitted compounds which are subject to reductions. The emission levels of the other compounds are unchanged compared to 1998 .

\begin{tabular}{|c|c|c|c|c|c|c|c|c|c|c|c|c|c|c|c|c|}
\hline \multirow[t]{2}{*}{ SNAP3 Code } & \multirow[t]{2}{*}{ Emitting activity } & \multicolumn{5}{|c|}{ Emission levels of scenario SC1 } & \multicolumn{5}{|c|}{ Emission levels of scenario SC2 } & \multicolumn{5}{|c|}{ Comparison of $\mathrm{SC} 2 / \mathrm{SC} 1$} \\
\hline & & $\mathrm{SO}_{2}$ & $\mathrm{NO}_{\mathrm{x}}$ & $\mathrm{CO}$ & VOC & $\mathrm{CH}_{4}$ & $\mathrm{SO}_{2}$ & $\mathrm{NO}_{\mathrm{x}}$ & $\mathrm{CO}$ & VOC & $\mathrm{CH}_{4}$ & $\mathrm{SO}_{2}$ & $\mathrm{NO}_{\mathrm{x}}$ & $\mathrm{CO}$ & VOC & $\mathrm{CH}_{4}$ \\
\hline & Combustions & & & & & & & & & & & & & & & \\
\hline 010100 & Combustion in energy: public power (electricity) & 0.86 & 0.98 & & & & 0.11 & 0.965 & 0.12 & & & 0.128 & 0.985 & 0.12 & & \\
\hline 020103 & Commercial \& Institutional: combustion plants < $<0$ MW (boilers) & 0.55 & 0.98 & 0.97 & & & 0.23 & 0.955 & 0.74 & & & 0.418 & 0.975 & 0.763 & & \\
\hline 020202 & Residential plants: combustion plants $<50 \mathrm{MW}$ (boilers) & 0.54 & 0.98 & 0.92 & & & 0.24 & 0.955 & 0.74 & & & 0.44 & 0.975 & 0.74 & & \\
\hline 030100 & Comb. in manufacturing ind. (boilers. gas turbine and stat. engines) & 0.90 & 0.98 & & & & 0.83 & 0.952 & 0.38 & & & 0.92 & 0.97 & 0.38 & & \\
\hline \multirow[t]{2}{*}{030200} & Comb. in manufacturing ind. (process furnaces without contact) & 0.81 & 0.98 & & & & 0.72 & 0.97 & & & & 0.72 & 0.99 & & & \\
\hline & Production processes & & & & & & & & & & & & & & & \\
\hline 040400 & Processes in inorganic chemical industries & & 0.95 & & & & & 0.5 & & & & & 0.53 & & & \\
\hline 040500 & Processes in organic chemical industries (bulk production) & & 0.95 & & & & & 0.5 & & & & & 0.53 & & & \\
\hline 040602 & Paper pulp (kraft process) & & & & 0.5 & & & & & 0.3 & & & & & 0.6 & \\
\hline 040603 & Paper pulp (acid sulfite process) & & & & 0.5 & & & & & 0.3 & & & & & 0.6 & \\
\hline 040604 & Paper pulp (Neutral Sulphite Semi-Chemical process) & & & & 0.5 & & & & & 0.3 & & & & & 0.6 & \\
\hline 040610 & Roof covering with asphalt materials & & & & 0.5 & & & & & 0.5 & & & & & & \\
\hline 040611 & Road paving with asphalt & & & & 0.5 & & & & & 0.5 & & & 0.714 & & & \\
\hline 040612 & Cement production (decarbonizing) & & 0.7 & & & & & 0.5 & & & & & & & & \\
\hline 040614 & Lime production (decarbonizing) & & & & 0.5 & & & & & 0.5 & & & & & & \\
\hline 050400 & Liquid fuel distribution (except gasoline distribution) & & & & 0.2 & & & & & 0.01 & & & & & 0.05 & \\
\hline 050500 & Gasoline distribution & & & & & & & & & 0.01 & & & & & 0.01 & \\
\hline 050600 & Gas distribution networks & & & & & & & & & 0.01 & & & & & 0.01 & \\
\hline \multirow{3}{*}{060000} & Solvent and other product use & & & & & & & & & & & & & & & \\
\hline & Solvent and other product use & & & & 0.57 & & & & & 0.4 & & & & & 0.70 & \\
\hline & Road transport & & & & & & & & & & & & & & & \\
\hline 070100 & Passenger cars & 0.23 & 0.39 & 0.70 & 0.50 & 0.39 & 0.18 & 0.31 & 0.55 & 0.37 & 0.30 & 0.783 & 0.795 & 0.786 & 0.74 & 0.769 \\
\hline 070200 & Light duty vehicles (total weight $<3.5 \mathrm{t}$ ) & 0.13 & 0.16 & 0.37 & 0.27 & 0.42 & 0.11 & 0.12 & 0.29 & 0.21 & 0.32 & 0.846 & 0.75 & 0.784 & 0.778 & 0.762 \\
\hline 070302 & Heavy duty vehicles (total weight $>3.5 \mathrm{t}$ ) - Rural driving & 0.15 & 0.34 & 1.36 & 0.62 & 0.17 & 0.13 & 0.29 & 1.14 & 0.50 & 0.14 & 0.867 & 0.853 & 0.838 & 0.806 & 0.824 \\
\hline 070400 & Mopeds and motorcycles $\left(<50 \mathrm{~cm}^{3}\right)$ & 0.07 & 0.46 & 0.12 & 0.23 & 1.22 & 0.07 & 0.44 & 0.12 & 0.24 & 1.24 & & 0.956 & & 1.04 & 1.02 \\
\hline 070500 & Motorcycles $\left(>50 \mathrm{~cm}^{3}\right)$ & 0.14 & 1.35 & 0.60 & 0.64 & 1.19 & 0.15 & 1.46 & 0.66 & 0.66 & 1.23 & 1.07 & 1.08 & 1.10 & 1.03 & 1.03 \\
\hline \multirow[t]{2}{*}{070600} & Gasoline evaporation from vehicles & & & & 0.13 & & & & & 0.1 & & & & & 0.769 & \\
\hline & Waste treatment and disposal & & & & & & & & & & & & & & & \\
\hline 090201 & Incineration of domestic or municipal wastes & & 0.7 & & & & & 0.5 & & & & & 0.714 & & & \\
\hline 090202 & Incineration of industrial waste (except flaring) & & & & 0.5 & & & & & 0.5 & & & & & & \\
\hline 090203 & Torchères en raffinerie du pétrole & & & & 0.5 & & & & & 0.5 & & & & & & \\
\hline 090204 & Flaring in chemical industries & & & & 0.5 & & & & & 0.5 & & & & & & \\
\hline 090205 & Incineration of sludges from waste water treatments & & & & 0.5 & & & & & 0.5 & & & & & & \\
\hline 091000 & Other waste treatment & & & & 0.5 & & & & & 0.5 & & & & & & \\
\hline
\end{tabular}

reductions reach $30 \%$. For the mobile sources, especially road traffic, the incoming motor technology, the reformulation and the decrease of the weight sulphur content of car fuels are considered by the CETE to balance the increase of the volume road traffic. The same hypothesis has been made for air, railway and fluvial traffic. Biogenic emissions are supposed to remain the same.

The SC2 scenario is based on the same European regulations as $\mathrm{SC} 1$ but includes more restricting regulations that correspond to a regional political will to reduce emissions. For all the fixed installations of combustion, all charcoal fuel types are replaced by heating oil with all fuel oils containing $0.05 \mathrm{wt} \%$ of sulphur. Incoming improvements in heating technology reach those of the point sources leading to a reduction of $\mathrm{NO}_{\mathrm{x}}$ emission levels of $5 \%$ (compared to $2 \%$ in $\mathrm{SC} 1)$. For the other activity sectors involving combustion, emission reductions for $\mathrm{SO}_{2}$ go from $14 \%$ to $89 \%$, and $26 \%$ to $88 \%$ for $\mathrm{CO}$. The emissions due to the industrial processes for some specific activities are reduced to $50 \%$ for $\mathrm{NO}_{\mathrm{x}}$ and in a range between $50 \%$ and $99 \%$ for the VOCs. For instance, the $\mathrm{NO}_{\mathrm{x}}$ emissions are reduced by $50 \%$ in chemical industrial processes except for paper factories where the reduction reaches $70 \%$, and the VOC emissions from domestic waste incinerators are reduced by $50 \%$ (compared to $30 \%$ in SC1). For transports, the development of public transportation at local and regional scales (extension of bus and tramway networks, increase of urban pedestrian area) and additional constraints on personal cars at national level (increase of car fuel taxes, balancing of the diesel and gasoline prices) allow to reduce emissions from road traffic between $17 \%$ and $19 \%$ for $\mathrm{CO}, \mathrm{NO}_{\mathrm{x}}$ and $\mathrm{VOC}$ compared to the $\mathrm{SC} 1$. For the other traffic, this scenario considers a decrease of the diesel railway traffic and of fuel consumption (about 10\%) leading to lower the emissions by more than $50 \%$ (56\% for $\mathrm{SO}_{2}, 57 \%$ for $\mathrm{NO}_{\mathrm{x}} 54 \%$ for the VOCs and $60 \%$ for $\mathrm{CO}$ ). The air traffic emissions are reduced by $2 \%$ per year.

\subsection{Impacts of the scenarios SC1 and SC2 on regional air quality}

\subsubsection{Model specifications}

The simulations are performed using EZM and the numerical setup of the simulation is briefly summarized here. The modeling domain represents an area of $144 \mathrm{~km} \times 216 \mathrm{~km}$ with a prescribed grid of $36 \times 54$ points in the horizontal leading to a of $4 \mathrm{~km} \times 4 \mathrm{~km}$. In the vertical direction, 35 points are 

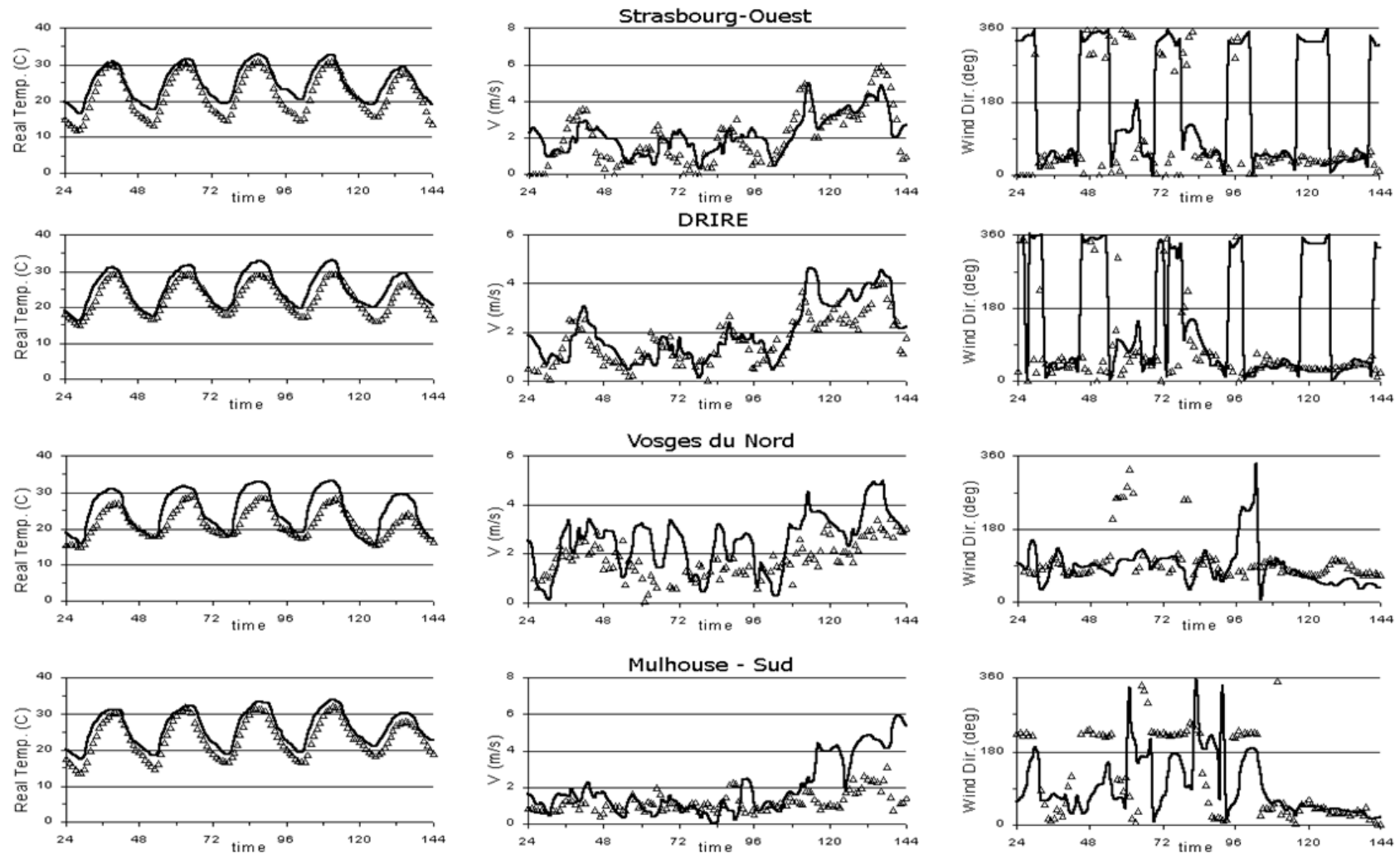

Fig. 5. Evolution of the temperature (first panel from left to right), horizontal wind intensity velocity (second panel) and direction (third panel) for a selection of the Alsacian measuring sites of the ASPA Air Quality survey network. The solid lines indicate the model results. The period represented is the 10 to 14 May 1998. "DRIRE" measuring station is located in the centre of the urban area of Strasbourg, "Strasbourg-Ouest" and "Mulhouse-Sud" are suburban measuring sites and "Vosges du Nord" is a rural one in a forested area (located $60 \mathrm{~km}$ North East of Strasbourg). All these locations are mentioned in Fig. 2.

used to represent $6 \mathrm{~km}$. The calculations are performed for the period of 9-14 May 1998. The initialization and boundary conditions are determined using vertical soundings provided by the ASPA for the first $1200 \mathrm{~m}$ and by the Deutsche Wetterdienst (DWD-Stuttgart, $100 \mathrm{~km}$ north-east from Strasbourg) for the altitudes above this height. The boundary conditions and the background concentrations of reactants are extracted from the regional network measurements done by the ASPA-Strasbourg. Therefore, the measurements from rural stations are used to evaluate the background ozone levels (around $70 \mathrm{ppb}$ ). A measurement station located in the core of the valley between Strasbourg and Karlsruhe, the so-called North-East Alsace, allows to take into account the urban plume coming form Karlsruhe region (with $\mathrm{NO}_{\mathrm{x}}$ levels around $9 \mathrm{ppb}$ ). Using these measurements, the ratio $\mathrm{NMVOC} / \mathrm{NO}_{\mathrm{x}}$ is estimated at 2.5. Keeping constant, in time and in space, the boundary conditions allow obtaining a clear analysis of the effect of the emission scenarios. In order to reduce the CPU demand, the chemical mechanism KOREM (Flassak et al., 1993) is used. This latter rather simple mechanism has shown its ability to account for ozone formation and depletion in the atmospheric boundary layer.

\subsubsection{Benchmark simulation result}

In Fig. 5, the time evolutions of the temperature (first panel from left to right), horizontal wind velocity (second panel) and direction (third panel) for a selection of the Alsacian meteorological sites are presented. The differences obtained in the temperature are mainly due the effect of averaging procedures on the topography and the land-use over $4 \times 4 \mathrm{~km}^{2}$. Nevertheless, the comparison between the measurements and the model results show a good agreement. One can notice that even the change of wind regime, i.e. from low to high geostrophic wind at the end of the week for the north part of the modeling domain, is reproduced with good accuracy. The time evolution of the ozone concentration for a selection of the Alsacian meteorological sites are presented in Fig. 6. Here also, the model results and the measurements are in a good agreement; the diurnal cycle is well reproduced even if the stations are close to or in urban areas and the horizontal resolution is $4 \times 4 \mathrm{~km}^{2}$.

Since the pollution situation was not dramatically changing from day to day, only the results obtained for a single day of simulation, e.g. 12 May are described (see Fig. 7). During 

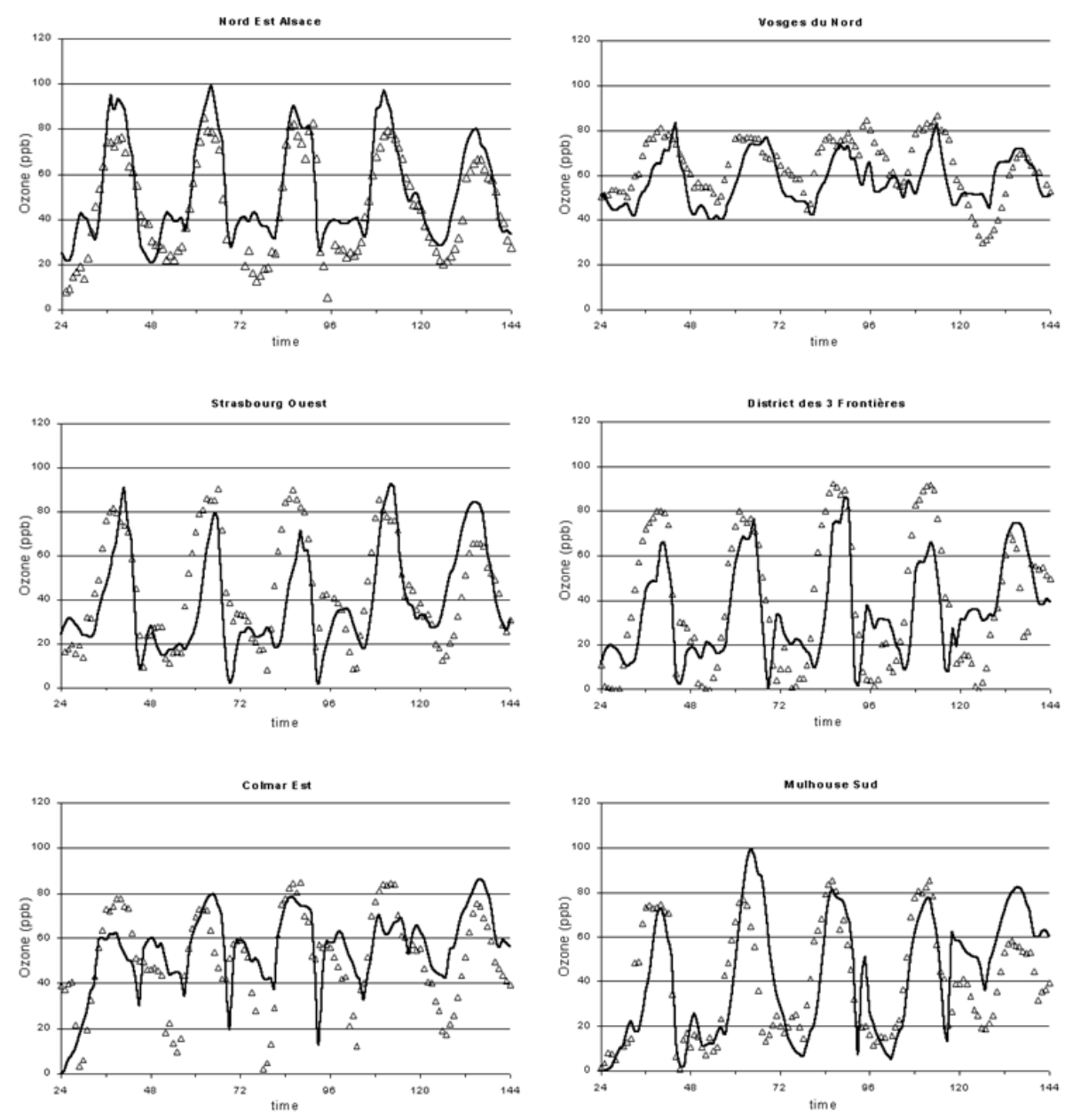

Fig. 6. Evolution of the ozone concentrations for a selection of the Alsacian pollutant measurement sites. The solid lines indicate the model results. The period represented is the 10 to 14 May 1998. "Nord-Est Alsace" and "Vosges du Nord" stations correspond to rural and mountainous sites located $60 \mathrm{~km}$ north east of Strasbourg and $90 \mathrm{~km}$ north of Strasbourg, respectively. "Strasbourg-Ouest", "Colmar-Est", and "Mulhouse-Sud" correspond to semi-urban measuring stations. The measuring station "District des 3 frontières" is also an semi urban one, located close to the Swiss-German- French border, south east of the domain. All theses sites are also indicated on the maps of Fig. 2.

the morning and the late afternoon, the wind flow is mainly driven by usual breeze phenomena that can be encountered in shallow valleys. Since the geostrophic wind shows low levels, the impacts of valley and mountain breezes are enhanced. Under such a low shear condition, the chemical transformations of the pollutants take place in a convective boundary layer driven mainly by turbulence during the day. As a result, the flow pattern over urban areas, such as Strasbourg or Mulhouse for instance, shows a strong turbulent structure. Nevertheless, since the shear is low, the pollutants are mainly not advected and the urban plume remains over the core of the valley.

In the early morning, ozone levels are driven by ozone depletion process due to NO. Therefore, the lowest ozone levels are found close to high NO emission sources such as urban areas or heavy traffic road. Over the mountainous areas, ozone levels are still high since they are related to the accu- mulation of the ozone produced the day before (no chemical sink in these regions). In the mid-morning, the breezes collapse and start to invert. As a result, the ozone produced in urban plumes transported by valley breezes enhances the ozone levels over the mountains. From this period until the late-afternoon, the production process of ozone in the whole valley becomes predominant. The combined contributions of the main city plumes allow the formation of high levels of ozone (more than $100 \mathrm{ppb}$ or $200 \mu \mathrm{g} / \mathrm{m}^{3}$ ) in almost the whole domain. At sunset, since the photolytic source of ozone collapses, the ozone levels over the cities or the core of the valley decrease dramatically. Over the rural regions, and particularly the mountains, ozone accumulates leading to the formation of ozone tanks reservoirs which remain during the night. 


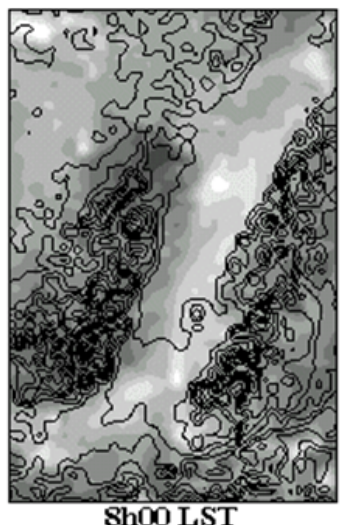

Sh00 LST

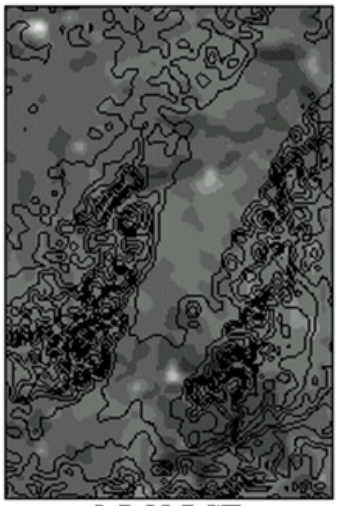

16h00 LST

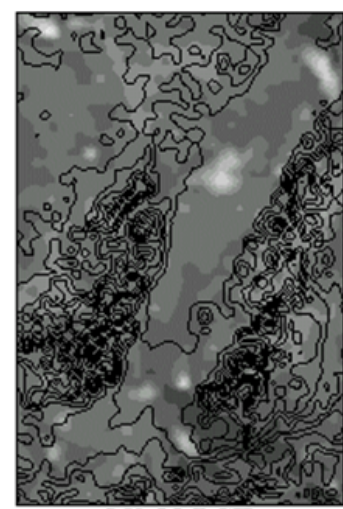

$12 \mathrm{~h} 00 \mathrm{LST}$

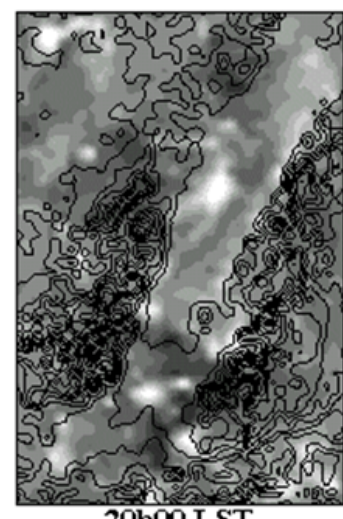

20 h00 LST

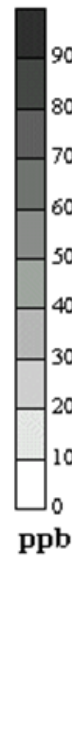

Fig. 7. Ozone concentration fields for 12 May 1998.

\subsubsection{Effects of the emission scenarios}

The results on the spatial distribution of the impacts show global improvement trends for the air quality over the whole region due to lower emissions. On the right hand side of Fig. 8, the percent change of the $\mathrm{NO}_{\mathrm{x}}$ concentration field for $\mathrm{SC} 1$ is presented. One can notice that this first scenario allows an important decrease of $\mathrm{NO}_{\mathrm{x}}$ levels over the whole domain which can reach even more than $90 \%$. For ozone, the reductions can reach more than $10 \mathrm{ppb}$ over areas where ozone levels show their maximum (see 1.h.s. of Fig. 8). Nevertheless, one can notice some increases of ozone levels in the urban areas, in spite of the reduction of primary pollutants. The tropospheric ozone levels are issued from a net balance between formation and destruction processes, and the chemical compounds which generate ozone are also taking part in its depletion. Formation and/or destruction depends in fact upon physical and chemical atmospheric conditions such as temperature, solar radiation, relative concentrations of $\mathrm{NO}_{\mathrm{x}}$, VOCs and especially $\mathrm{NO}_{\mathrm{x}} / \mathrm{VOC}$ ratios. In urban areas, during photochemical episodes, the emission of $\mathrm{NO}_{\mathrm{x}}$ and VOC leads to lower ozone levels with high daily variations compared to rural areas (including mountainous areas), where higher and more constant levels can be observed. The destruction of ozone is more efficient in urban

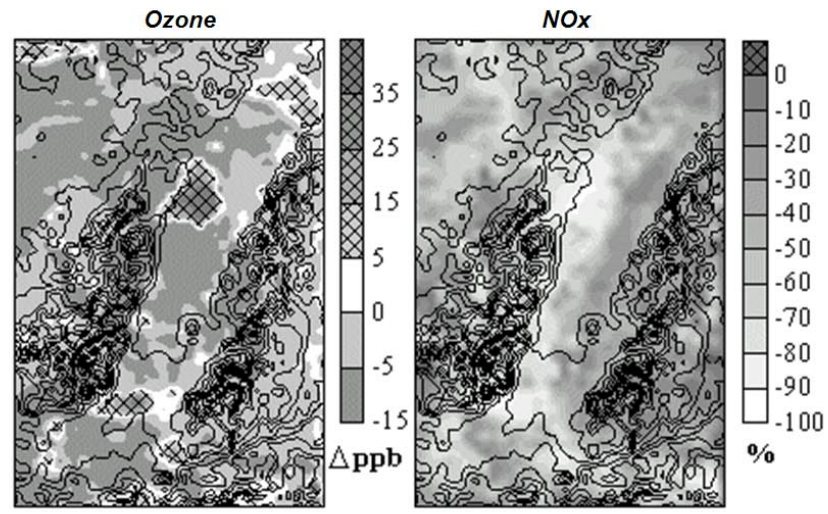

Fig. 8. Effects of $\mathrm{SC} 1$ on the concentration fields of ozone and $\mathrm{NO}_{\mathrm{x}}$ for 12 May 1998 at 13:00 LST. The left figure represents the difference between the scenario and the reference case for ozone. On the right figure, the percentage of increase of the $\mathrm{NO}_{\mathrm{x}}$ concentration field is given. Notice that in both cases a positive/negative value accounts for an increase/decrease of concentration. The topography is represented with solid lines.

areas due to higher emissions. Then, part of the urban ozone can be transported over rural areas where its destruction is low (due to lower emission levels). These processes lead to ozone accumulation over this type of area. The effects of the reduction emission scenarios are to modify the ozone balance by decreasing the ozone destruction rather than the generation over the urban areas and by lowering the ozone production and accumulation over the rural areas. Similar results are obtained for $\mathrm{SC} 2$.

For $\mathrm{SC} 1$, the impacts on the $\mathrm{NO}_{\mathrm{x}}$ concentrations are much more significant than those for ozone. A general decrease of up to $90 \%$ of $\mathrm{NO}_{\mathrm{x}}$ concentrations is observed. This means that the emission abatement strategy seems very efficient. SC2 allows a higher decrease up to $30 \%$ compared to SC1 on the main part of the domain. However a small increase of $\mathrm{NO}_{\mathrm{x}}$ is calculated for $\mathrm{SC} 2$ over the area of Karlsruhe (10 $15 \%$ as compared to SC1). This can be explained by the fact that the SC2 concerns only the Alsace region. As mentioned previously, the major effect of the large decrease of the $\mathrm{NO}_{\mathrm{x}}$ concentrations is the decrease of ozone in rural and mountainous areas and the increase of the ozone concentrations in the highly urbanized area.

An alternative to evaluate the impact of emission scenarios on air quality is to define parameters that can be used to evaluate the concept of threshold and accumulated levels of pollutants. Studies of the impacts of ozone on agricultural crops and forests have resulted in the establishment of critical levels using long-term exposure measures. One of these measures is the accumulated excess ozone (Fuhrer and Achermann, 1991). This index is referred to as AOTX that represents the accumulated excess of ozone over a threshold of X ppb. In fact several AOT can be defined. In this paper, we focus on the AOT40, AOT55 and AOT60. These 

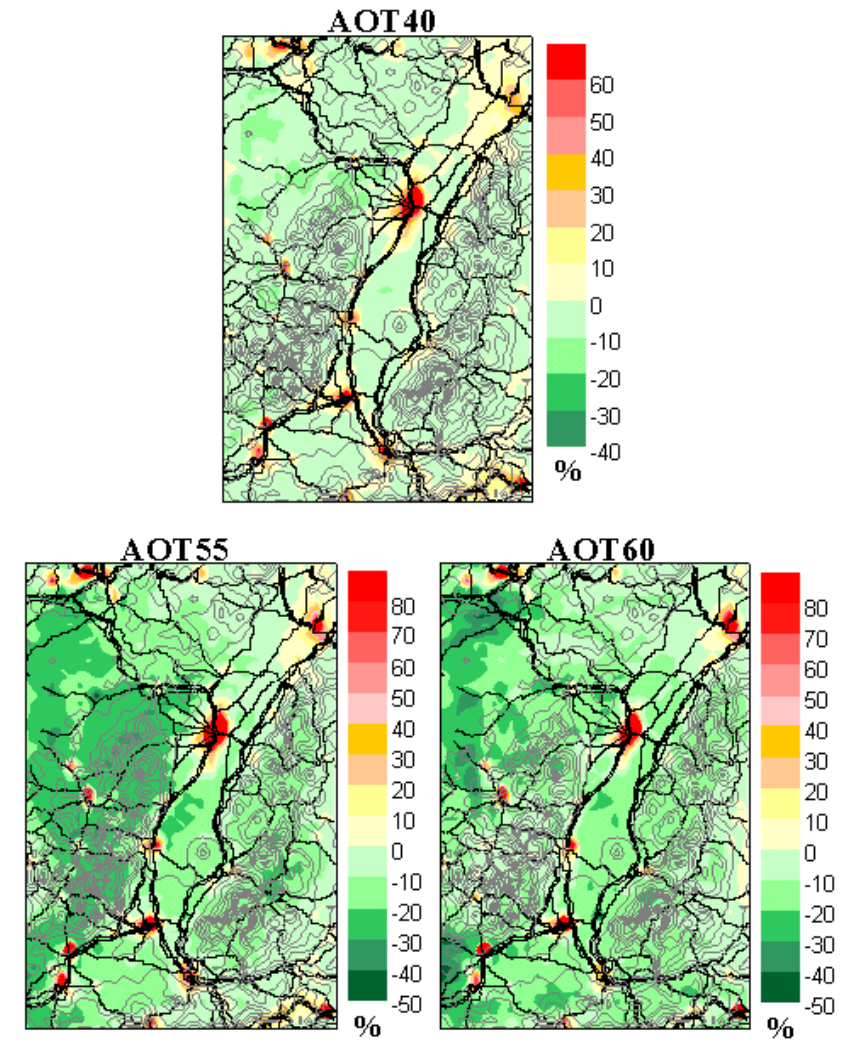

Fig. 9. Effects of the SC1 on the AOT40, 55 and 60.

AOT represent the total cumulative amount of ozone levels higher then $40 \mathrm{ppb}$ as an hourly average during daytime, higher than $55 \mathrm{ppb}$ as an hourly average between 13 and 20 LST and higher than $60 \mathrm{ppb}$ as daily maxima, respectively. These parameters are calculated for the whole period of the experiment. Figure 9 shows the effect of $\mathrm{SC} 1$ on such parameters. Some general conclusions can be drawn from this figure. The background levels of ozone, as represented by the AOT40, are reduced by approximately $10 \%$ in the main part of the valley. The highest daily value of ozone (AOT55) and the daily maximum of ozone (AOT60) are reduced by 10 to $40 \%$ everywhere apart from the urban areas where the increase of the AOT55 and the AOT60 can reach 70\%. These results show a global trend of improved air quality standards by applying the emission scenarios. Nevertheless, as mentioned previously, the ozone levels and, thus the AOTs, are increasing in urban areas. Since the emission scenarios are based on the reduction of the emission of ozone precursors such as $\mathrm{NO}_{\mathrm{x}}$, and since, in these areas, the ozone is driven by depletion processes such as oxidation by NO, the ozone depletion is less efficient. On the other hand, the generation of ozone in urban plumes is lower and the AOTs are decreasing in the rural areas that constitute the main parts of the valley.

A first step to estimating the population exposure to ozone pollution is to determine the surface of the domain concerned by high levels of ozone. We determine the surface where
Table 6. Total daily surface concerned by the excedance of the European information threshold for ozone. The surfaces are given in $\mathrm{km}^{2} \cdot \mathrm{h}$.

\begin{tabular}{lccc}
\hline & Benchmark & Scenario SC1 & Scenario SC2 \\
\hline Sun. May 10 & 16572 & 12914 & 12989 \\
Mon. May 11 & 25605 & 16274 & 15154 \\
Tue. May 12 & 41356 & 8510 & 7614 \\
Wed. May 13 & 26351 & 15527 & 15229 \\
Thu. May 14 & 9854 & 4330 & 4255 \\
\hline Average & 23947.6 & 11511.0 & 11048.2 \\
\hline
\end{tabular}

ozone levels are exceeding the hourly information threshold of ozone (e.g. $180 \mu \mathrm{g} \mathrm{m}^{-3} \times 1 \mathrm{~h}$ of ozone exposition). As a result, we access a population exposure index that is expressed in square kilometers - hour units. In Table 6, we present the total daily surface (area of the domain $\times 24 \mathrm{~h}$ ) where ozone levels are exceeding the information threshold for the ozone calculated for the reference case (where no emission scenario is used) and for the scenario SC1 and SC2. One can notice that the hourly-areas affected by the overflow of this threshold are reduced by applying emission regulation scenarios. In fact, for the whole pollution episode, these areas are reduced by more than $50 \%$. The next step of this study could be to correlate these numbers with the amount of people living in such areas and the sub-grid topography. Then it will be possible to estimate the population exposure to pollution.

\section{Summary and conclusion}

We have illustrated the possible use of emission scenario for air quality management purpose by presenting the effect of three emission abatement strategies: the impact of the installation of the urban tramway in the old centre of Strasbourg, the use of oxygenated and reformulated car fuels at local and regional scales, and the application of the future European regulations. In this latter application, which is the most refined, the results show global improvement trends for the air quality over the whole region due to lower emissions (between 10 and $90 \%$ of general decrease for $\mathrm{NO}_{\mathrm{x}}$ and between 5 and $25 \%$ of decrease in rural and mountainous areas for ozone). Nevertheless, there are some increases in ozone levels (up to $30 \%$ ) in the urban areas in spite of the reduction of primary pollutants. This can be explained by considering that the tropospheric ozone levels are the results of a net balance between formation and destruction processes. Formation and/or destruction depend in fact upon physical and chemical conditions of the atmosphere such as temperature, solar radiation, relative concentrations of $\mathrm{NO}_{\mathrm{x}}$, VOCs and especially upon the $\mathrm{NO}_{\mathrm{x}} / \mathrm{VOC}$ ratios. The use of reformulated 
and oxygenated fuels at regional scale allows a great improvement in the VOC levels and in particular on moderately and highly reactive alkanes, aromatics, ketones and PAN for all the fuels. Some VOC trends such as the ones of alkenes and aldehydes show a dependence on the type of fuels used. For those, it seems that the oxygenated fuel blend (ETBE1) is the most appropriate fuel to be used to reduce their levels. Nevertheless, using both reformulation and oxygenation (ETBE2) gives poorer results than using only reformulation (R2). The impacts of using alternate fuel blends are more important at the regional scale than at the local scale but they show similar trends. This study also allowed us to show a significant increase of $\mathrm{NO}_{\mathrm{x}}$ levels at the regional scale whereas, at the local scale, the trend for $\mathrm{NO}$ is a moderate increase of concentrations and the positive impacts on $\mathrm{NO}_{2}$ in the urban centre were balanced by the negative impacts in the surrounding areas. The simulated ozone levels are slightly lowered at regional scale and more important reductions can be noticed locally (greater than $10 \%$ ).

We have shown that the possibilities of the impact studies are numerous according to the comprehensive knowledge of the generation emission processes. Various strategies can be tested in air using scenarios and air quality models to create emission regulations consistent with the socioeconomic context. Further steps using emission scenarios to improve the results will be (1) to include long-range transport of pollutant and variable boundary conditions for the primary and secondary pollutant concentrations in the areas of study and (2) to apply the scenarios to typically representative days throughout the year (excluding photochemical pollution episodes), and to quantify the impact of abatement strategies on the average pollutant background concentrations.

Acknowledgements. The authors are grateful to the EEC and the French National authority - the "Direction Régionale de l'Industrie, de la Recherche et de l'Environnement (DRIRE) of Alsace" and which have funded these studies and supported J.-F. Vinuesa. We thank the Regional air quality network measurement (ASPA) and the CETE de l'Est for providing data for the PRQA study. The authors thank the reviewer for his comments and suggestions which have helped to improve the quality of the paper.

Edited by: L. M. Frohn

\section{References}

Adrian, G. and Fiedler, F.: Simulation of unstationary wind and temperature fields over complex terrain and comparison with observations, Beitr. Phys. Atmosph., 64, 27-48, 1991.

Alcamo, J., Mayerhofer, P., Guardans, R., van Harmelen, T., van Minnen, J., Onigkeit, J., Posch, M., and de Vries, B.: An integrated assessment of regional air pollution and climate change in Europe: findings of the AIR-CLIM Project, Environ Sci. and Policy, 5-4, 257-272, 2002.
Collins, W. J., Stevenson, D. S., Johnson, C. E., and Derwent, R. G.: The European regional ozone distribution and its links with the global scale for the years 1992 and 2015, Atmos. Environ., 34, 255-267, 2000.

Chang, Y.-S., Arndt, R. L., Calori, G., Carmichael, G. R., Streets, D. G., and Su, H.: Air quality impacts as a result of changes in energy use in China's Jiangsu Province, Atmos. Environ., 32, 1383-1395, 1998.

Derwent, R. G., Stevenson, D. S., Collins, W. J., and Johnson, C. E.: Intercontinental transport and the origins of the ozone observed at surface sites in Europe, Atmos. Environ., 38-13, 1891-1901, 2004.

EEA: COPERT III Computer program to calculate emissions from road transport - Methodology and emission factors and User Manual, Technical reports No 49 and No 50, http://reports. eea.eu.int/Technical_report_No_49/ and http://reports.eea.eu.int/ Technical_report_No_50/, 2000.

EEA: EMEP-CORINAIR - Emission Inventory Guidebook - 3rd edition Technical report No 30, Published by European Environment Agency (last version: Jan. 2002), Kgs. Nytorv 6, DK1050 Copenhagen, Denmark, http://reports.eea.eu.int/technical_ report_2001_3/, 2002.

Flassak, Th. and Kessler, Ch.: Development of an EURAD zooming model and first preparation for the "joint EUMAC dry case" simulations, in: Photooxidants: Precursors and Products, edited by: Borell, P. M., Borell, P., Cvitas, T., and Seiler, W., 461-464, 1993.

François, S., Grondin, E., Fayet, S., and Ponche, J.-L.: The establishment of the atmospheric emission inventories of the ESCOMPTE program, Atmos. Res., 74, 5-35, 2005.

Fuhrer, J. and Achermann, B.: Critical levels for ozone, UN-ECE Workshop Report, FAC No. 16, Swiss Federal Research Station for Agricultural Chemistry and Encironmental Hygiene, Switzerland, 1991.

Gallardo, J. C., Khatami, A., Vinuesa, J.-F., Ponche, J.-L., and Mirabel, Ph.: Modélisations de la qualité de l'air et étude de sensibilité de la région du Grand Casablanca (Maroc), Publications de l'Association Internationale de Climatologie, 12, 442450, 1999.

Gallardo, J. C.: Etudes de la qualité de l'air - Réalisation d'inventaires d'émissions atmosphériques et modélisation de la formation de polluants photochimiques, $\mathrm{PhD}$ thesis, Louis Pasteur University of Strasbourg (France), 2000.

INTERREG II: Analyse transfrontalière de la qualité de l'air dans le Rhin supérieur - Grenzübergreifende Luftqualitätsanalyse am Oberrhein", Communauté de travail - Arbeitgemeinschaft ASPA (Association pour la Surveillance et l'étude de la pollution atmosphérique en Alsace) UMEG (Gesellschaft für Umweltmessungen und Umwelterhebungen $\mathrm{mbH}$ ), Official document, edited by: Holler, H. W. und Verlag GmbH, Killisfeldstrasse 45, D-76227 Karlsruhe (Germany), 2000.

Khatami, A., Ponche, J.-L., Jabry, E., and Mirabel, Ph.: The Air quality management of the region of Great Casablanca (Morocco), Part 1: Atmospheric emission inventory for the year 1992, The Science of the Total Environment, 209, 201-216, 1998.

Mayerhofer, P., de Vries, B., den Elzen, M., van Vuuren, D., Onigkeit, J., Posch, M., and Guardans, R.: Long-term, consistent scenarios of emissions, deposition, and climate change in 
Europe, Environ. Sci. and Policy, 4-5, 273-305, 2002.

Metcalfe, S. E., Whyatt, J. D., Derwent, R. G., and O’Donoghue, M.: The regional distribution of ozone across the British Isles and its response to control strategies, Atmos. Environ., 36-25, 4045-4055, 2002.

Moussiopoulos, N.: The Eumac Zooming Model, a tool for local-toregional air quality studies, Meteorolog. Atmos. Phys., 57, 115133, 1995.

Moussiopoulos, N., Sahm, P., Karatzas, K., Papalexiou, S., and Karagiannidis, A.: Assessing the impact of the new athens airport to urban air quality with contemporary air pollution models, Atmos. Environ., 31, 1497-1511, 1997.

Pallarès, C., Ponche, J.-L., Fayet, S., and Mirabel, Ph.: L'inventaire des émissions horaires de la région de Strasbourg pour la période du 8 au 15 mai 1998, Report PRIMEQUAL, edited by: Association de Surveillance et d'études de la Pollution atmosphérique en Alsace (ASPA), 5 rue de Madrid, F-67309 Schiltigheim Cédex (France), 1999a.

Pallarès, C., Mirabel, Ph., and Ponche, J.-L.: Modélisation d'un épisode de pollution à l'ozone sur l'agglomération de Strasbourg pour la période du 09 au 14 mai 1998, Final report PRIMEQUAL-PREDIT, edited by: Association de Surveillance et d'études de la Pollution atmosphérique en Alsace (ASPA), 5 rue de Madrid, F-67309 Schiltigheim Cédex (France), 1999b.

Pallarès, C., Mirabel, Ph., and Ponche, J.-L.: Cadastre des émissions de polluants atmosphériques dues aux petites installations de combustion pour la région Alsace en 1997, Final report for the Regional Plan for Air Quality (PRQA) and INTERREG II programme (Transboundary analysis of the air Quality of the Upper Rhine Valley), edited by: Association de Surveillance et d'études de la Pollution atmosphérique en Alsace (ASPA), 5 rue de Madrid, F-67309 Schiltigheim Cédex (France), 160, 1999c.
Ponche, J.-L., Ghannouchi, R., Oudin, V., and Mirabel, Ph.: L'inventaire des émissions atmosphériques franco-allemand pour la Communauté Urbaine de Strasbourg et l'arrondissement de l'Ortenau (Kehl-Offenburg), The French-German atmospheric emission inventory for the urban community of StrasbourgOrtenau ward (Kehl-Offenburg), Pollution Atmosphérique, 148, 74-88, 1995.

Ponche, J.-L., Schneider, Ch., and Mirabel, Ph.: Methodology and results of the REKLIP atmospheric emission inventory of the upper Rhine valley transborder region, Water, Soil and Air Pollution, 124, 61-93, 2000.

PRQA: Plan Régional de la qualité de l'air en Alsace - Approuvé par arrêté préfectoral $\mathrm{n}^{\circ} 265$ du décembre 2000 , Ed. Valbor, F67400 Illkirch, Février 2001, ISBN 2-84488-025-8, 2000.

REKLIP: Atlas climatique du fossé Rhénan méridional, Vol. 1, texte et 2 volumes cartes, ISBN 2-903297-097-5, Ed. COPRUR, F67000 Strasbourg, 1995.

REKLIP: Qualité de l'Air et Climat Régional/LuftQualität und Regionalklima, Rapport final, Vol. 3, Schlussbericht Band 3, ISBN 2-84208-035-1, Ed. COPRUR, F-67000 Strasbourg, 1999.

Schneider, Ch., Kessler, Ch., and Moussiopoulos, N.: Influence of emission input data on ozone level predictions for the Upper Rhine valley, Atmos. Environ., 31, 3187-3205, 1997.

Vinuesa, J.-F.: Modélisation de la qualité de l'air: Impact à l'échelle locale et régionale de l'utilisation de carburants automobiles modifiés, PhD thesis, L. Pasteur University of Strasbourg I, 2000.

Vinuesa, J.-F., Mirabel, Ph., and Ponche J.-L.: Air quality effects of using reformulated and oxygenated gasoline fuel blends: Application to the Strasbourg area (F), Atmos. Environ., 37, 17571774, 2003. 